\title{
MAXIMAL PERIOD OF CRYOPRESERVATION WITH THE BICELL BIOFREEZING VESSEL FOR RAT TRACHEAL ISOGRAFTS
}

Ryoichi Nakanishi, MD, PhD, FICS

Mitsunori Hashimoto, MD

Hiroyuki Muranaka, MD

Masayoshi Umesue, MD, $\mathrm{PhD}$

Hiroyuki Kohno, MD, PhD

Kosei Yasumoto, MD, PhD
Objective: The maximal period of cryopreservation for the trachea is still unsolved. We assessed the maximal period of cryopreservation using the Bicell biofreezing vessel as an easy and cheap slow-freezing instrument for viable tracheal grafts in 95 rats. Methods: Each isograft was harvested from 17 donor rats, immersed in the preservative solution, and stored in a Bicell device in a deep freezer at $-80^{\circ} \mathrm{C}$. The tracheal isografts were then randomly assigned to 9 groups according to cryopreservation periods ranging from 0 to 12 months. Included in the 9 groups were 2 subgroups ( $n=6$ per subgroup) that were observed immediately after being thawed and 1 month after heterotopic transplantation into the omentum after being thawed. Four subgroups ( $n=6$ per subgroup) were added according to the cryopreservation period for $1,3,6$, and 12 months to evaluate the graft morphology 3 months after being thawed and transplanted heterotopically. Results: A prolonged period of cryopreservation had a degenerative effect on both the epithelium and cartilage. One month after transplantation, degeneration was more pronounced in the cartilage than in the epithelium, as characterized by the viable chondrocyte ratio and the epithelial score of isografts undergoing cryopreservation for more than 9 months. Three months after transplantation, the morphology of the epithelium and cartilage in isografts undergoing cryopreservation for less than 3 months was better preserved, whereas the morphology of both deteriorated in isografts undergoing cryopreservation for more than 6 months. Conclusions: We conclude that the permissible period of cryopreservation to maintain tracheal isograft viability in this simple system using a Bicell biofreezing vessel is 3 months. (J Thorac Cardiovasc Surg 1999;117:1070-6)
A lthough transplantation of the trachea is considered to be the preferred method for the reconstruction of extensive tracheal defects in the future, the deficit of donor trachea will remain a major obstacle. This prob-

From the Second Department of Surgery, School of Medicine, University of Occupational and Environmental Health, Kitakyushu, Japan.

This study was supported by a Research Grant for Immunology, Allergy and Organ Transplant, Ministry of Health and Welfare, and a Grant-in-Aid (08671555) from the Ministry of Education, Science, and Culture of Japan.

Received for publication Dec 2, 1998; revisions requested Jan 28, 1999; revisions received Feb 15, 1999; accepted for publication Feb 26, 1999.

Address for reprints: Ryoichi Nakanishi, MD, PhD, FICS, Assistant Professor, Second Department of Surgery, School of Medicine, University of Occupational and Environmental Health, 1-1 Iseigaoka, Yahatanishi-ku, Kitakyushu 807, Japan.

Copyright (C) 1999 by Mosby, Inc.

$0022-5223 / 99 \$ 8.00+0 \quad \mathbf{1 2 / 1 / 9 8 2 2 4}$ lem remains unsolved in the trachea, as in most organs in which transplantation has been clinically performed. A long-term period of preservation is one of the methods to help solve this problem. However, such preservation is generally difficult under usual temperature conditions.

Cryopreservation of the trachea has been experimentally attempted, probably because of its simple structure, ${ }^{1,2}$ and that of cardiac valves and cartilage has already been practiced in a clinical setting for the same reasons. ${ }^{3,4}$ The effect of cryopreservation on tracheal grafts remains to be elucidated. We first investigated the effect of cryopreservation on tracheal isografts in this study. In clinical use, an easy and cheap system of cryopreservation is desirable. We thus assessed the maximal period of cryopreservation for viable grafts when a simple and gradual freezing vessel was used in this study. We used isografts to avoid the immunologic complexity of allografts. A prolonged period and an easy system 
of cryopreservation could help us to resolve the shortage of donors.

\section{Materials and methods}

Animals and anesthesia. The heterotopic tracheal transplant model with omental wrapping was used with a technique modified for rats., ${ }^{5,6}$ Ninety-five male Lewis rats between 10 and 12 weeks of age and weighing approximately 250 to $300 \mathrm{~g}$ were premedicated with anesthetic ether. The animals were placed in the supine position and anesthetized with sodium pentobarbital $(10 \mathrm{mg} / \mathrm{kg}$ given intraperitoneal1y). Under spontaneous ventilation without an endotracheal tube, either harvesting or transplantation was performed. All animals received humane care in compliance with the "Guide for the Care and Use of Laboratory Animals" published by the National Institutes of Health (NIH Publication No. 85-23, revised 1985).

Harvesting and cryopreservation. A total of 132 tracheal segments consisting of 3 rings were harvested from 17 donor rats. Through a midline cervical to sternal incision, the whole trachea was identified and excised in continuity. The wound was closed in the usual fashion. The harvested trachea was trimmed off in 3-ring segments. Twelve tracheal segments served as controls and are termed "fresh isografts." The remaining 120 segments were then immediately stored in a plastic sterile tube filled with the freezing solution. The preservative solution in which the grafts were immersed contained a balanced buffered salt solution with L-glutamine (RPMI-1640 medium; JRM Biosciences, Lenexa, Kan) with a final concentration of $20 \%$ fetal calf serum and $10 \%$ dimethyl sulfoxide (DMSO) as a cryoprotectant. The plastic tube containing the specimen was then stored in a Bicell biofreezing vessel (Nihon Freezer Co, Ltd, Tokyo, Japan) and subsequently stored in a deep freezer at $-80^{\circ} \mathrm{C}$. The Bicell device has the ability to cool down at a rate of approximately $1^{\circ} \mathrm{C}$ per minute in a deep freezer until reaching $-80^{\circ} \mathrm{C}$.

Experimental design and grafting. Cryopreserved isografts were thawed in an incubator for 15 minutes at $37^{\circ} \mathrm{C}$ for grafting. The tracheal isografts were randomly assigned to 9 groups according to the cryopreservation period for 0 to 12 months $(0,0.25=1$ week; $0.5=2$ weeks; $1,2,3,6,9$, and 12 months), including 2 subgroups ( $\mathrm{n}=6$ per subgroup): subgroup a, observation immediately after the tissue was thawed; subgroup b, observation 1 month after the tissue was thawed and transplanted heterotopically. Four subgroups $(n=6$ per subgroup) were added according to the cryopreservation period, that is, for $1,3,6$, and 12 months, and were evaluated as subgroup c 3 months after heterotopic transplantation after thawing (Table I). The isografts in subgroups $b$ and $c$ of groups 1 to 9 were stented over a silicone rod $1.35 \mathrm{~mm}$ in diameter (ATOM, Inc, Tokyo, Japan) and then were heterotopically implanted into the omentum of 78 recipient rats. A silicone rod was used to prevent the omentum from intruding into the graft. The recipient animals were placed in the supine position. Through a small upper midline laparotomy, the
Table I. Experimental design

\begin{tabular}{|c|c|c|c|}
\hline $\begin{array}{l}\text { Groups } \\
(n=6 \\
\text { per group) }\end{array}$ & $\begin{array}{l}\text { Cryopreservation } \\
\text { period (mo) }\end{array}$ & $\begin{array}{c}\text { Heterotopic } \\
\text { transplantation }\end{array}$ & $\begin{array}{c}\text { Transplantation } \\
\text { period (mo) }\end{array}$ \\
\hline 1a & 0 & - & 0 \\
\hline $1 \mathrm{~b}$ & 0 & + & 1 \\
\hline $2 \mathrm{a}$ & 0.25 & - & 0 \\
\hline $2 b$ & 0.25 & + & 1 \\
\hline $3 a$ & 0.5 & - & 0 \\
\hline $3 b$ & 0.5 & + & 1 \\
\hline $4 a$ & 1 & - & 0 \\
\hline $4 \mathrm{~b}$ & 1 & + & 1 \\
\hline $4 c$ & 1 & + & 3 \\
\hline $5 a$ & 2 & - & 0 \\
\hline $5 b$ & 2 & + & 1 \\
\hline $6 a$ & 3 & - & 0 \\
\hline $6 \mathrm{~b}$ & 3 & + & 1 \\
\hline $6 c$ & 3 & + & 3 \\
\hline $7 a$ & 6 & - & 0 \\
\hline $7 b$ & 6 & + & 1 \\
\hline $7 \mathrm{c}$ & 6 & + & 3 \\
\hline $8 a$ & 9 & - & 0 \\
\hline $8 b$ & 9 & + & 1 \\
\hline $9 a$ & 12 & - & 0 \\
\hline $9 \mathrm{~b}$ & 12 & + & 1 \\
\hline $9 \mathrm{c}$ & 12 & + & 3 \\
\hline
\end{tabular}

-, Not done; +, done; 0.25 months $=1$ week; 0.5 months $=2$ weeks.

greater omentum was delivered into the wound. The anterior layer of the omentum was opened, and the tracheal transplant was completely enveloped. The omentum and the enclosed transplant were then returned to the peritoneal cavity, and the wound was closed. After 1 or 3 months, a second laparotomy was performed in 9 groups to retrieve the transplants for histopathologic analysis.

Histopathologic assessment. All tissue specimens were fixed in 10\% formalin. Microscopic slides were made from cross sections of the midportion of the tracheal segment and adherent omentum and were stained routinely with hematoxylin and eosin. Thereafter, all specimens were examined with a light microscope. We attempted to quantify the viability of the heterotopically grafted trachea by subjectively evaluating the epithelial structure and objectively calculating the ratio of chondrocytes possessing a viable nucleus in the cartilage. The assessment was performed in a blinded fashion.

Epithelial viability. Epithelial viability was evaluated according to the following grading system: 0 , no epithelium; 1 , a single layer of nonciliated epithelium; 2 , multiple layers of nonciliated epithelium; and 3, normal mucociliary epithelium. The epithelium of the grafts was assessed as a ratio of the epithelial score on a microscopic slide., ${ }^{7,8}$

Cartilage viability. The ratio of chondrocytes possessing viable nuclei in the cartilage of each transplant was calculated after carefully counting the number of all chondrocytes in each high-power field on a microscopic slide. A viable chondrocyte nucleus was regarded as richly stained and possessing a clear nuclear membrane. 


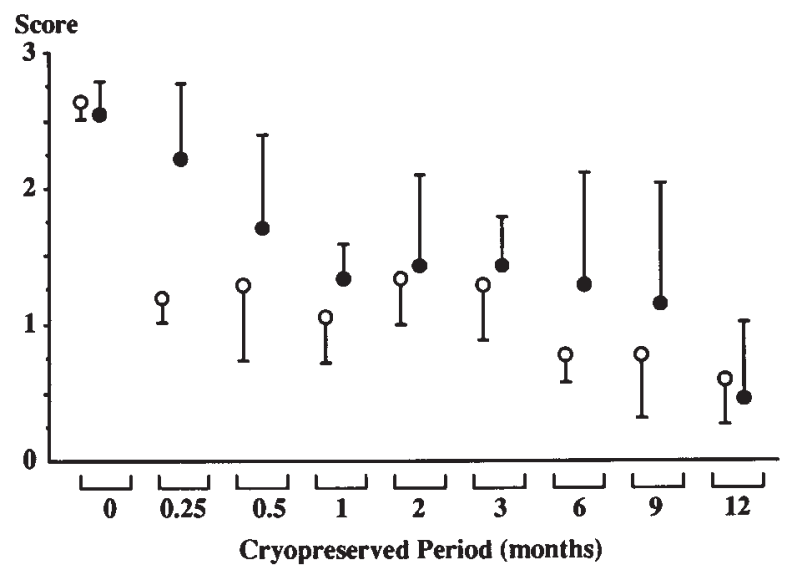

Fig 1. The epithelial score (mean \pm standard deviation of the mean) of tracheal isografts in subgroup a (open circles) and of those in subgroup b (closed circles). Zero months' cryopreservation designates the fresh trachea isografts. The epithelial score in subgroup b was significantly better than that in subgroup a in the isografts cryopreserved for 0.25 month (1 week) $(P=.02)$.

Statistical analysis. All data were presented as the mean \pm standard deviation of the mean. A statistical analysis was performed with the paired Student $t$ test.

\section{Results}

Gross appearance. The omentum was wrapped firmly around the tracheal isografts in all rats. Grossly, all free tracheal isografts appeared normal and also preserved their luminal rigidity.

Histopathology. Isografts in subgroups a and $\mathrm{b}$ in groups 1 to 9 , according to the period of cryopreservation, showed the histologic characteristics of the epithelium and cartilage to worsen gradually, but not to a critical extent. The free isografts had little infiltration of inflammatory cells or submucosal thickening by fibrous tissue.

Epithelial viability. The epithelium of the isografts immediately after being thawed was partially denuded. The remaining epithelium showed degeneration and was separated from the submucosal tissue. The epithelial score of the cryopreserved isografts immediately after thawing, irrespective of the period of cryopreservation, was significantly worse than that of the fresh isografts (Fig 1, subgroup a). In subgroup b, likewise, the score of the isografts undergoing cryopreservation for 0.5 to 12 months was significantly worse than that of the fresh isografts (Fig 1, subgroup b). However, some isografts that underwent the same treatment after cryopreservation for less than 9 months showed that the epithelium was often regenerated at the membranous portion and had partially normal mucociliary epithelium. The epithelial score of the isografts undergoing heterotopic transplantation after being thawed showed a little better trend than that of the isografts immediately after being thawed for each period of cryopreservation except for 12 months (Fig 1). The tracheal isografts of subgroup c showed 2 types of epithelial morphology, including regeneration and degeneration. In the epithelial score of those isografts, significant differences were observed between 1 or 3 and 6 or 12 months of cryopreservation (Table II). Some isografts cryopreserved for 1 or 3 months demonstrated more mucociliary or multilayer epithelium in subgroup c than in subgroup $\mathrm{b}$ (Fig 2, $A$ and $B$ ). In contrast, the isografts cryopreserved for 6 or 12 months tended to show an exacerbated score by means of a prolonged period of transplantation treatment (Table II), and the isografts of subgroup c had a partially single or multilayer nonciliated epithelium.

Cartilage viability. The cartilage viability of the isografts showed an exacerbating trend as the period of cryopreservation increased. Immediately after the tissue was thawed, the ratio of viable chondrocytes in the isografts cryopreserved for more than 1 month was significantly less than that of the fresh isografts (Fig 3, subgroup a). Likewise, the ratio of viable chondrocytes of the isografts undergoing a heterotopic transplantation after cryopreservation for 2 to 12 months was significantly less than that of fresh isografts (Fig 3, subgroup b). Especially in the isografts cryopreserved for more than 9 months, the ratio of viable chondrocytes of isografts in subgroup b was significantly less than that of isografts in subgroup a; by contrast, no difference was seen in the ratio of viable chondrocytes of the isografts undergoing cryopreservation for less than 6 months between subgroups $a$ and $b$ (Fig 3). Tracheal isografts undergoing cryopreservation for less than 3 months in subgroup $\mathrm{c}$ had some viable cartilage islands and also showed new chondrocytes in the adventitial area (Fig 2, $A$ and $B$ ). In contrast, the isografts undergoing cryopreservation for more than 6 months in subgroup c showed an exacerbating trend according to the length of the cryopreservation period and also had nonviable chondrocyte nuclei in the lacunae. Above all, the isografts undergoing cryopreservation for 6 months in subgroup c showed a significantly worse ratio than those undergoing the same preservation in subgroup $\mathrm{b}$ $(P=.02)$ (Table III).

\section{Discussion}

We previously studied graft viability,, 10 rejection reaction, ${ }^{5}$ minimal immunosuppression, ${ }^{6,11}$ and recon- 


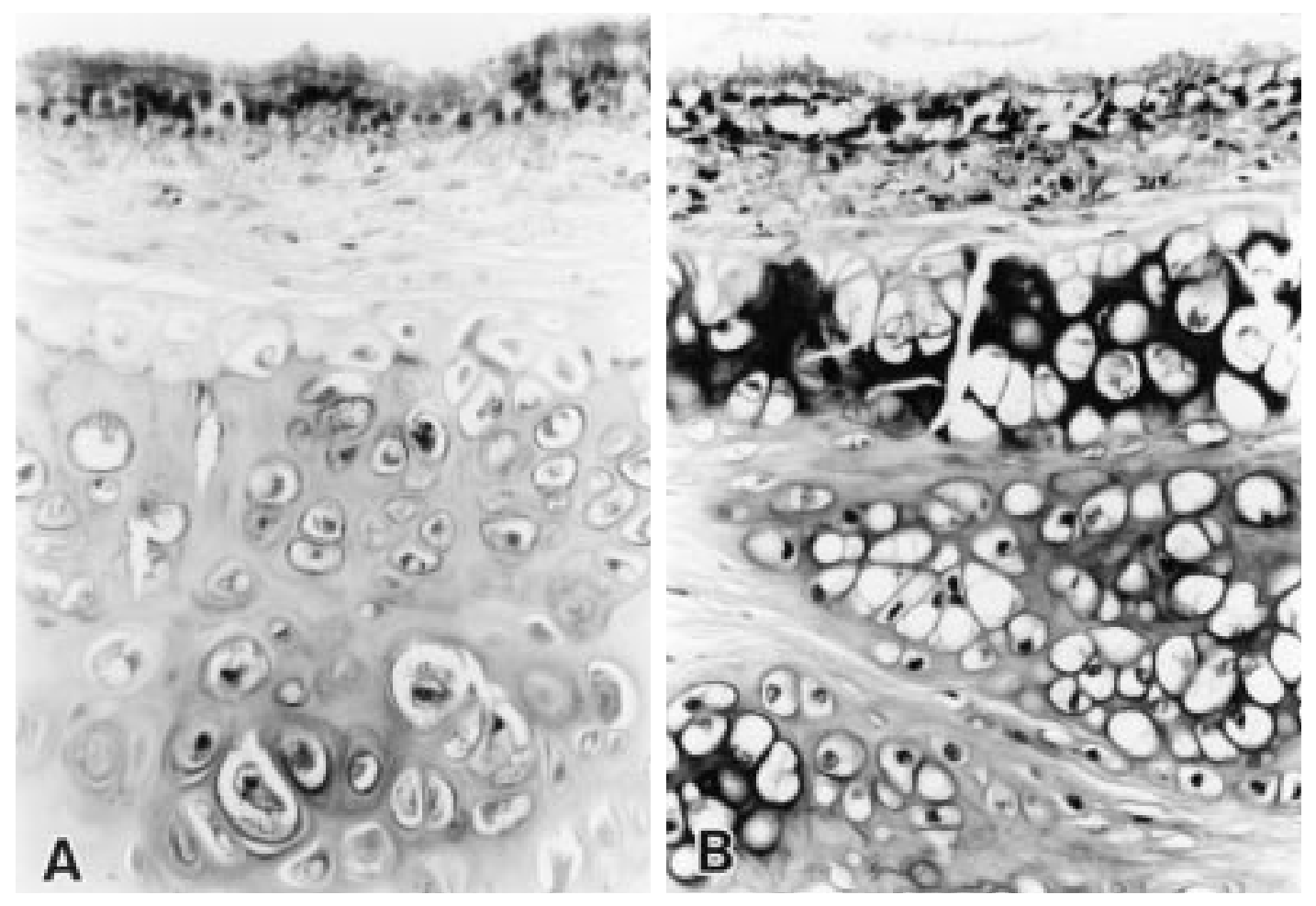

Fig 2. Micrographs of tracheal isografts 3 months after transplantation. A, Group 4c. Normal mucociliary epithelium is recognized extensively. The cartilage has viable chondrocyte nuclei and cytoplasm filled with viscous liquid in the lacunae. B, Group 6c. Mucociliary epithelium with goblet-like cells is often recognized. The cartilage has viable chondrocyte nuclei but the amount of viscous liquid has decreased in the cytoplasm. New chondrocytes are seen in the adventitial area. (Hematoxylin and eosin; original magnification, $\times 400$.)

struction range $\mathrm{e}^{7-9,12,13}$ in tracheal allotransplantation for eventual clinical use in human beings. As a result, graft viability was maintained by omental wrapping. ${ }^{9,10}$ The epithelial morphology of the graft was closely associated with the rejection reaction. ${ }^{5}$ Minimal immunosuppression using a minimal dose of cyclosporin A (Sandoz Pharma AG, Basel, Switzerland) (INN: ciclosporin) or a short course of mizoribine (Bredinin; Asahikasei Co, Ltd, Tokyo, Japan) was feasible.6,11 Extensive airway reconstruction involving the carina was feasible with the use of a long-segment graft by the application of basic fibroblast growth factor or a shortsegment graft under conditions of anastomotic tension of less than $1.0 \mathrm{~kg}{ }^{7,8,12,13}$ The preservation of the trachea, however, is still unsolved. We therefore studied the long period of cryopreservation for viable tracheal isografts.

Generally, cryopreservation of biomaterials is initiated by a slow-freezing system, which is composed of a computer-controlled unit that freezes at a rate of $1^{\circ} \mathrm{C}$ to $5^{\circ} \mathrm{C}$ per minute until reaching $-80^{\circ} \mathrm{C}$ to $-100^{\circ} \mathrm{C} .{ }^{14}$ The

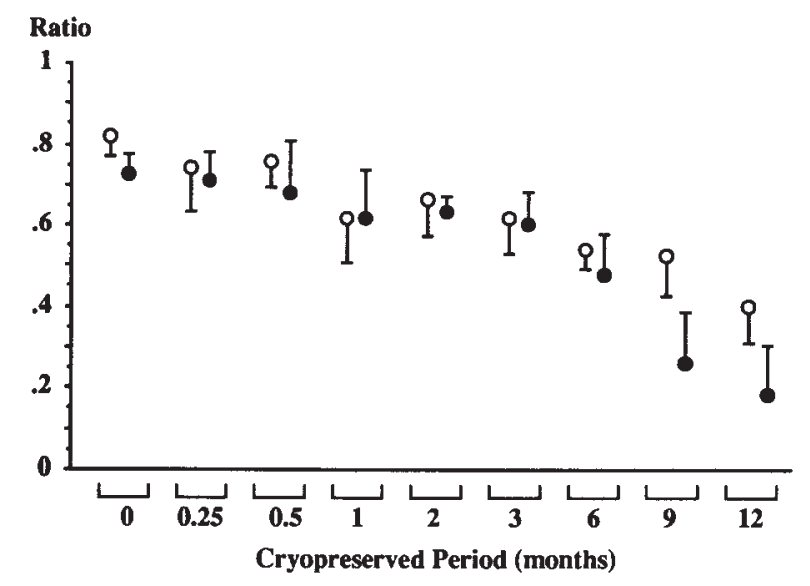

Fig 3. The ratio of viable chondrocytes (mean \pm standard deviation of the mean) of tracheal isografts in subgroup a (open circles) and of those in subgroup b (closed circles). Zero months' cryopreservation designates the fresh tracheal isografts. The viable chondrocyte ratio in subgroup b was significantly worse than that in subgroup a in the isografts cryopreserved for 0,9 , and 12 months $(P=.04, .01$, and .01 , respectively). 
Table II. Epithelial score of tracheal isografts

\begin{tabular}{|c|c|c|c|c|}
\hline \multirow[b]{2}{*}{ Treatment after thawing } & \multicolumn{4}{|c|}{ Cryopreservation period (mo) } \\
\hline & 1 & 3 & 6 & 12 \\
\hline Absent & $1.055 \pm 0.357 *($ group $4 a)$ & $1.283 \pm 0.422^{* \dagger}($ group $6 \mathrm{a})$ & $0.767 \pm 0.216($ group $7 a)$ & $0.550 \pm 0.302($ group $9 a)$ \\
\hline $\begin{array}{l}\text { Heterotopic } \\
\text { transplantation } \\
\text { for } 1 \mathrm{mo}\end{array}$ & $1.300 \pm 0.276^{*}$ (group $\left.4 \mathrm{~b}\right)$ & $1.433 \pm 0.339^{*}$ (group 6b) & $1.267 \pm 0.826$ (group 7b) & $0.467 \pm 0.528$ (group 9b) \\
\hline $\begin{array}{l}\text { Heterotopic } \\
\text { transplantation } \\
\text { for } 3 \mathrm{mo}\end{array}$ & $1.750 \pm 1.253^{* \dagger}$ (group $\left.4 \mathrm{c}\right)$ & $1.700 \pm 0.494 *($ group $6 c)$ & $0.250 \pm 0.418$ (group 7c) & $0.183 \pm 0.133$ (group 9c) \\
\hline
\end{tabular}

Table III. Viable chondrocyte ratio of tracheal isografts

\begin{tabular}{|c|c|c|c|c|}
\hline \multirow[b]{2}{*}{ Treatment after thawing } & \multicolumn{4}{|c|}{ Cryopreservation period (mo) } \\
\hline & 1 & 3 & 6 & 12 \\
\hline Absent & $0.622 \pm 0.113^{*}($ group $4 \mathrm{a})$ & $0.622 \pm 0.093 *$ (group 6a) & $0.545 \pm 0.054 \ddagger($ group $7 \mathrm{a})$ & $0.405 \pm 0.093 \div($ group $9 a)$ \\
\hline $\begin{array}{l}\text { Heterotopic } \\
\text { transplantation } \\
\text { for } 1 \mathrm{mo}\end{array}$ & $0.612 \pm 0.128^{*}($ group $4 b)$ & $0.597 \pm 0.085^{*}$ (group $\left.6 \mathrm{~b}\right)$ & $0.475 \pm 0.103 \ddagger($ group $7 b)$ & $0.190 \pm 0.114$ (group 9b) \\
\hline $\begin{array}{l}\text { Heterotopic } \\
\text { transplantation } \\
\text { for } 3 \text { mo }\end{array}$ & $0.629 \pm 0.170^{*} \dagger($ group $4 \mathrm{c})$ & $0.544 \pm 0.070 * \dagger($ group $6 c)$ & $0.323 \pm 0.054 *($ group $7 \mathrm{c})$ & $0.181 \pm 0.068$ (group 9c) \\
\hline
\end{tabular}

*The viable chondrocyte ratio in each group was significantly better than that in the 12-month cryopreservation group at the same treatment course (group $4 \mathrm{a}$ vs $9 \mathrm{a}$, $P=.04$; group 6a vs $9 \mathrm{a}, P=.01$; group $4 \mathrm{~b}$ vs $9 \mathrm{~b}, P=.002$; group $6 \mathrm{~b}$ vs $9 \mathrm{~b}, P=.0001$; group $4 \mathrm{c}$ vs $9 \mathrm{c}, P=.003$; group $6 \mathrm{c}$ vs $9 \mathrm{c}, P=.0006$; group $7 \mathrm{c}$ vs $9 \mathrm{c}, P=.01$. $†$ The viable chondrocyte ratio in each group was significantly better than that in the 6-month cryopreservation group at the same treatment course (group $4 \mathrm{c}$ vs $7 \mathrm{c}$, $P=.004$; group $6 \mathrm{c}$ vs $7 \mathrm{c}, P=.0004)$.

$¥$ The viable chrondrocyte ratio in each treatment group was significantly better than that in the 3-month transplantation group at the same cryopreservation period (group 7a vs 7c, $P=.0001$; group $7 \mathrm{~b}$ vs $7 \mathrm{c}, P=.02$; group $9 \mathrm{a}$ vs $9 \mathrm{c}, P=.005$ ).

Bicell biofreezing vessel stored in a deep freezer at $-80^{\circ} \mathrm{C}$ has almost the same ability as slow-freezing instruments when compared with computer-controlled units. This vessel potentially prevents deterioration of cell viability subsequent to the transient heat release that occurs during crystallizing. ${ }^{15}$ Moreover, this vessel is inexpensive and does not require a high running cost. Cryopreservation with this vessel is thus considered to be potentially acceptable at many institutions, and we decided to use this vessel in our study.

Several studies on the effects of cryopreservation on the trachea have been conducted. Deschamps and colleagues ${ }^{1}$ demonstrated that the gross anatomy of tracheal autografts was maintained after cryopreservation for 1 week, but a microscopic examination was not necessarily done. Cryopreserved autografts showed normal epithelium, but the cartilage was abnormal as characterized by a loss of chondrocyte nuclei in the lacunae. In contrast, Yokomise and associates ${ }^{2}$ reported that a 1-month cryopreservation did not affect the morphology of either the epithelium or the cartilage. Some differences exist in the cryopreserving methods, cryopreservation periods, and cryoprotective agents between both of these studies. Theoretically, the former study must show better preservation of cartilage than the latter study because of the use of a computer-controlled freezing system, the cryopreservation system using liquid nitrogen $\left(-196^{\circ} \mathrm{C}\right)$, and the shorter-term cryopreservation. In fact, the latter study, in which a simple cryopreservation was performed, showed a better preserved cartilage. Cryoprotectants using trehalose and DMSO potentially played an important role in the viability of the cartilage in the latter study. However, the results of their study are still open to question because no fine evaluation for cartilage was performed. Therefore the synergistic effect of these cryoprotectants still remains obscure. In this study, we used DMSO alone as a cryoprotective agent in the same way 
as Deschamps and colleagues ${ }^{1}$ because it is the most standard and well-established method. . $^{3,4,14,16,17}$

Our careful evaluation of the histologic morphology of the tracheal isografts suggested a prolonged period of cryopreservation to have a degenerative effect on both the epithelium and the cartilage. The cartilage showed more degeneration than the epithelium, as characterized by the viable chondrocyte ratio and the epithelial score of isografts treated with a 1-month transplantation after cryopreservation for more than 9 months. This may be one of the reasons that the cryoprotectant did not penetrate deeply into the cartilage. Cryopreserved tracheal isografts that are transplanted heterotopically are considered to require a long period to restore their structural integrity owing to damage during cryopreservation. We assessed the tracheal structure 3 months and 1 month after syngeneic transplantation in view of previously investigated canine tracheal transplantation models. ${ }^{9}, 10$ The prolonged period of transplantation thus showed the permissible period of cryopreservation for tracheal isografts. The morphology of the epithelium or cartilage in the isografts undergoing a cryopreservation period of less than 3 months was improved or maintained, respectively. In contrast, the prolonged period of transplantation showed deterioration in the morphology in both the epithelium and cartilage in isografts undergoing cryopreservation for more than 6 months. Essentially, the prolonged period of transplantation should improve the wound healing of the graft in the tracheal autotransplantation model. ${ }^{7-10}$ Therefore a cryopreservation period of more than 6 months definitely negatively influences the graft morphology in this system.

This limitation of the cryopreservation period is mainly due to the temperature of cryopreservation. The cellular membrane is subject to impairment during long-term cryopreservation at more than $-130^{\circ} \mathrm{C}$ because that temperature tends to cause intracellular recrystallization. ${ }^{18}$ Therefore liquid nitrogen $\left(-196^{\circ} \mathrm{C}\right)$ is required as a future strategy for long-term cryopreservation, and using it would promise a longer period of cryopreservation. Other reasons for the limitations of the cryopreservation period potentially include the cold shock that occurs during the course of freezing and thawing injury. ${ }^{19,20}$ In this experiment, the Bicell device as the freezing instrument, DMSO as the cryoprotectant, and RPMI-1640 and fetal calf serum as the medium to keep osmotic pressure balance were used to prevent cold shock. The cryopreserved isografts were then thawed in the standard fashion to prevent any intracellular recrystallization or unbalanced osmotic pressure. ${ }^{20}$ Therefore such factors are not considered to have a greater effect on the period of cryopreservation than the temperature during cryopreservation.

In conclusion, cryopreservation for more than 6 months worsened the viability of both the epithelium and cartilage of tracheal isografts according to the length of the transplantation period, whereas cryopreservation for less than 3 months either improved or maintained their viability. The permissible period of cryopreservation in this simple system using the Bicell device is thus considered to be 3 months. Cryopreservation for 3 months at $-80^{\circ} \mathrm{C}$ in this system is considered to be acceptable in the clinical setting of many institutions because of its low cost and simplicity.

We thank Ms Miki Kiyofuji for her skillful technical assistance.

\section{REFERENCES}

1. Deschamps C, Trastek VF, Ferguson JL, et al. Cryopreservation of canine trachea: functional and histological changes. Ann Thorac Surg 1989;47:208-12.

2. Yokomise H, Inui K, Wada H, Hasegawa S, Ohno N, Hitomi S. Reliable cryopreservation of trachea for one month in a new trehalose solution. J Thorac Cardiovasc Surg 1995;110:382-5.

3. Kirklin JK, Smith D, Novick W, et al. Long-term function of cryopreserved aortic homografts: a ten-year study. J Thorac Cardiovasc Surg 1993;106:154-66.

4. Hartog JM, Slavin AB, Kline SN. Reconstruction of the temporomandibular joint with cryopreserved cartilage and freeze-dried dura: a preliminary report. J Oral Maxillofac Surg 1990;48: 919-25.

5. Nakanishi R, Shirakusa T, Hanagiri T. Early histopathologic features of tracheal allotransplantation rejection: a study in nonimmunosuppressed dogs. Transplant Proc 1994;26:3715-8.

6. Nakanishi R, Yasumoto K. Minimal dose of cyclosporin A for tracheal allografts. Ann Thorac Surg 1995;60:635-9.

7. Nakanishi R, Nagaya N, Yoshimatsu T, Hanagiri T, Yasumoto K. Optimal dose of basic fibroblast growth factor for long-segment orthotopic tracheal autografts. J Thorac Cardiovasc Surg 1997; 113:26-36.

8. Nakanishi R, Hashimoto M, Yasumoto K. Improved airway healing using basic fibroblast growth factor in a canine tracheal autotransplantation model. Ann Surg 1998;227:446-54.

9. Nakanishi R, Shirakusa T, Mitsudomi T. Maximum length of tracheal autografts in dogs. J Thorac Cardiovasc Surg 1993;106: 1081-7.

10. Nakanishi R, Shirakusa T, Takachi T. Omentopexy for tracheal autografts. Ann Thorac Surg 1994;57:841-5.

11. Nakanishi R, Yasumoto K, Shirakusa T. Short-course immunosuppression after tracheal allotransplantation in dogs. J Thorac Cardiovasc Surg 1995;109:910-7.

12. Takachi T, Shirakusa T, Nakanishi R, et al. Experimental carinal autotransplantation and allotransplantation. J Thorac Cardiovasc Surg 1995;110:762-7.

13. Nakanishi R, Hashimoto M, So T, Sugaya S, Yasumoto K. Successful tracheo-carinal transplantation. J Cardiovasc Surg. In press. 
14. Hopkins RA. Cardiac reconstructions with allograft valve. New York: Springer-Verlag; 1989. p. 55-8.

15. Lange PL, Hopkins RA. Allograft valve banking: techniques and technology. In: Hopkins RA, editor. Cardiac reconstructions with allograft valve. New York: Springer-Verlag; 1989. p. 37-63.

16. Messineo A, Filler RM, Bahoric A, Smith CR. Repair of long tracheal defects with cryopreserved cartilaginous allografts. J Pediatr Surg 1992;27:1131-5.
17. Kawabe N, Yoshinao M. Cryopreservation of cartilage. Int Orthop 1990;14:231-5.

18. Karow AM, Pegg DE. Organ preservation for transplantation. New York: Marcel Dekker; 1981. p. 118.

19. Smith AU, Polge C. Survival of spermatozoa at low temperature. Nature 1950;166:668.

20. Bank HL, Brockbank K. Basic principles of cryobiology. J Card Surg 1987;2(suppl):137-43.

\section{Availability of Journal back issues}

As a service to our subscribers, copies of back issues of The Journal of Thoracic and Cardiovascular Surgery for the preceding 5 years are maintained and are available for purchase from Mosby at a cost of $\$ 17.00$ per issue until inventory is depleted. The following quantity discounts are available: $25 \%$ off on quantities of 12 to 23, and one third off on quantities of 24 or more. Please write to Mosby, Inc, Subscription Services, 11830 Westline Industrial Drive, St Louis, MO 63146-3318, or call 800-453-4351 or 314-453-4351 for information on availability of particular issues. If unavailable from the publisher, photocopies of complete issues may be purchased from UMI, $300 \mathrm{~N}$ Zeeb Rd, Ann Arbor, MI 48106, 313-761-4700. 